\title{
Vibration Signals and Condition Monitoring for Wind Turbines
}

\author{
Dimitrios Koulocheris, Georgios Gyparakis, Andonios Stathis, Theodore Costopoulos* \\ School of Mechanical Engineering, National Technical University of Athens, Athens, Greece \\ Email: *cost@central.ntua.gr
}

Received October 8, 2013; revised November 8, 2013; accepted November 15, 2013

Copyright (c) 2013 Dimitrios Koulocheris et al. This is an open access article distributed under the Creative Commons Attribution License, which permits unrestricted use, distribution, and reproduction in any medium, provided the original work is properly cited.

\begin{abstract}
Rolling element bearings are critical parts of modern wind turbines as they carry the loads of the turning structure and the wind force. The stochastic nature of the wind loads makes it difficult to estimate the useful operational life of the bearings. Condition monitoring of these bearings in a real time environment could be very helpful in estimating their performance and in scheduling maintenance actions when a condition-based maintenance strategy is followed. This procedure can be successfully implemented by using vibration analysis in the time domain or in the frequency domain, giving useful results about the current condition of bearings and the location of potential faults. Permanently located transducers on proper positions on the bearings' housings can be used in order to collect, process and evaluate real time measurements and provide information about the bearing's performance. In this work, a test rig is utilized in order to evaluate the performance of rolling bearings. The results of the experimentation are satisfactory and the progress of fatigue failures can be predicted through vibration analysis techniques showing that implementation in real scale may be useful.
\end{abstract}

Keywords: Wind Turbines; Bearings; Basic Rating Life; Maintenance; Condition Monitoring; Vibration Signals

\section{Introduction}

In preventive maintenance, predetermined actions take place between scheduled time intervals. Most of the time, critical parts of machinery are replaced as they reach their useful operational life, based on previous experience regarding their rated life. This maintenance strategy often increases the total cost as the residual life of these parts is wasted and some unnecessary preventive actions take place. In order to minimize this cost, it is necessary to schedule the preventive maintenance actions according to the actual performance needs and operating conditions of each machine. The main aspects of this conditionbased maintenance approach are the proper diagnosis of the current condition and the prognosis of its future evolution.

Wind turbines are often installed at places which are difficult to be reached. It would be helpful to establish a condition monitoring system on these wind turbines in order to evaluate the current condition and performance of them and their major parts. Many diagnostic tools are used in order to estimate and monitor the current condi-

*Corresponding author. tion of a machine part. One of these tools is vibration signal analysis which is a largely used and effective tool for the diagnosis of the current condition of rotating equipment where the increased vibrations are indicative for an abnormal performance.

In this paper, we experimentally evaluate vibration signal analysis methods for rotating shafts and rolling element bearings under various load and operating conditions. The analysis can be performed in the time domain and/or in the frequency domain and a relationship between the vibration signals and the evolution of a failure or wear is investigated.

\section{Vibration Signal Analysis on Wind Turbines}

Wind turbines often exhibit malfunctions due to shaft misalignment, imbalance and bearing failures. These failures are common in rotating equipment and they result in increased vibration levels. This vibration can be measured close to its source, but often it can be detected on other elements which are in contact. In this case increased noise is affecting the signal [1-3]. 
Displacement, velocity and acceleration transducers can be used to extract these vibration signals. The most common arrangement is the use of an accelerometer which is permanently attached on the machine shell or even better on the bearing housing. The accelerometer can measure the excitation in one direction or even in three if it is a tri-axial one. The signal is processed in order to retrieve the desired characteristics and to reduce the noise. This can be achieved with the use of appropriate frequency filters (low-high pass filters, Wiener filter) and the compensation of the systemic noise [4-7]. After the initial signal processing, data can be further processed in the time or in the frequency domain.

\subsection{Vibration Analysis in Time Domain}

In time domain, data are processed with statistical and numerical methods. The most common values that are measured or calculated are $[8,9]$ :

1) The minimum and the maximum amplitude (minmax).

2) The peak count.

3) Mean $\mu$ and standard deviation $\sigma$ :

$$
\mu=\frac{1}{n} \sum_{i=0}^{n} x_{i}
$$

$$
\sigma=\sqrt{\frac{1}{n} \sum_{i=0}^{n}\left(x_{i}-\mu\right)^{2}}
$$

4) Root Mean Square (RMS):

$$
x_{r m s}=\sqrt{\frac{1}{n} \sum_{i=0}^{n}\left(x_{i}\right)^{2}}
$$

5) The crest factor (peak to average).

6) Statistical moments of higher order such as skewness $S$ and kurtosis $K$ :

$$
\begin{array}{r}
S=\frac{\frac{1}{n} \sum_{i=0}^{n}\left(x_{i}-\mu\right)^{3}}{\sigma^{3}} \\
K=\frac{\frac{1}{n} \sum_{i=0}^{n}\left(x_{i}-\mu\right)^{4}}{\sigma^{4}}
\end{array}
$$

\subsection{Vibration Analysis in Frequency Domain}

Certain faults and malfunctions exhibit signal peaks in characteristic frequencies. Depending on the nature of the faults, peaks occur at different characteristic frequen-

\begin{tabular}{|c|c|c|}
\hline Cause/element & Characteristic Frequency & Remarks \\
\hline Unbalance & $1 \times f$ & $f=$ Shaft Rotation Frequency \\
\hline Angular misalignment & $1 \times f$, lower at $2 \times f, 3 \times f$ & \\
\hline Parallel misalignment & $2 \times f$, lower at $1 \times f, 3 \times f$ & \\
\hline Bent shaft & $1 \times f$, lower at $2 \times f$ & \\
\hline Internal looseness & $2 \times f$, lower at its harmonics & \\
\hline Structure looseness & $2 \times f$, lower at its harmonics & \\
\hline \multirow{4}{*}{ Bearings (rolling) } & $f_{c}=\frac{f}{2}\left(1-\frac{D}{d} \cos a\right)$ & Cage Rotating Frequency \\
\hline & $f_{b p o r}=Z \frac{f}{2}\left(1-\frac{D}{d} \cos a\right)$ & Ball Pass Frequency of Inner Raceway \\
\hline & $f_{b p i r}=Z \frac{f}{2}\left(1+\frac{D}{d} \cos a\right)$ & Ball Pass Frequency of Outer Raceway \\
\hline & $f_{r}=\frac{f}{2} \frac{d}{D}\left[1-\left(\frac{D}{d} \cos a\right)^{2}\right]$ & Ball Spin Frequency \\
\hline \multirow{3}{*}{ Gears } & $f_{1}, f_{2}$ & $f_{i}=$ Rotation Frequency of Gear i \\
\hline & $G M F=z_{i} \times f_{i}, G M F \pm 1 \& 2 \times f_{i}$ & Gear Mesh Frequency \\
\hline & $H T=\frac{G M F \times C F\left(z_{1}, z_{2}\right)}{z_{1} \times z_{2}}$ & $\begin{array}{l}\text { Hunting Tooth Frequency, } \\
C F=\text { common factors }\end{array}$ \\
\hline Aerodynamic vibrations & $f_{a}=f \times n$ & $n=$ Number of Blades \\
\hline \multirow{3}{*}{ Electrical faults } & $f_{L}, \quad 2 \times f_{L}$ & Electric Line Frequency \\
\hline & $f_{S}=\left(2 \times f_{L}\right) / P-$ actual speed & Slip Frequency \\
\hline & $f_{P}=f_{S} \times P, \quad 2 \times f_{P}$ & Pole Frequency \\
\hline Natural component frequencies & & \\
\hline
\end{tabular}
cies. The most common causes of these vibrations in the case of wind turbines and their characteristic frequencies are shown on Table 1.

Table 1. Wind turbine potential faults characteristic frequencies. 
Data which have been recorded in the time domain are can easily be represented in the frequency domain with the use of a Fourier transformation. The most common Fourier transform method is the Discrete Time Fourier Transform (DTFT) which is calculated efficiently with the use of a Fast Fourier Transform (FFT) algorithm. In the frequency domain various types of analyses can be performed such as spectral analysis, cepstrum analysis or bispectral analysis [10].

Many researchers have shown satisfactory results in diagnosing and predicting the evolution of bearing faults using various vibration analysis techniques [11-15]. Most of the times, the diagnosis of a fault is based on observations regarding changes in the measured characteristics (peak counts, increase in magnitude, extreme variation). Artificial intelligence (AI) and artificial neural networks (ANN) are new areas of research [16-19]. ANNs are trained to observe signals that correspond to an abnormal operation. With the use of decision trees [20,21] and fuzzy logic [22], various parameters are evaluated in order to decide whether a failure has occurred.

Most studies regard experimental setups with minimum distortion and low noise to affect the measured signals. Laboratory conditions and specific setups (where the bearing under testing differs from the rest) help in measuring the vibration signals produced by faults in preliminary or advanced stages with low signal noise. In most real life situations things are more complicated. Vibrations and noise are introduced into the signal due to the following reasons: angular and axial misalignment, shaft imbalance, improper support and fixings, electrical noise, transducer position, and load variation. These parameters are limiting the use of time domain analysis as the magnitude of the measured signal is dominated mostly by noise rather than the measured characteristic. In these situations, frequency domain analysis seems to present more useful results.

\section{Experiments}

\subsection{Setup}

The main components of a wind turbine are shown in Figure 1. In the experimental setup a simplified model has been created including the blades (simulated by an applied weight force), the shaft, the bearings of the shaft, the motor/generator and the flexible coupling between the motor and the shaft. For reasons of simplicity, other major components of wind turbines, such as disk brakes or gear boxes are not currently integrated on this setup.

The schematic of the bearing test rig on which the experiments are carried out is shown in Figure 2.

In Figure 3, a photo of the test rig is shown. The rig consists from a concrete platform based on four rubber bumpers and a $30 \mathrm{~mm}$ diameter shaft supported by two

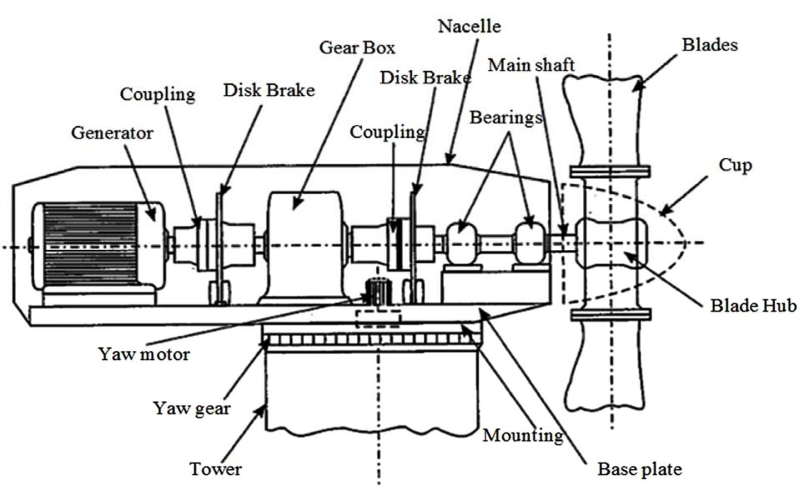

Figure 1. Wind turbine major parts.

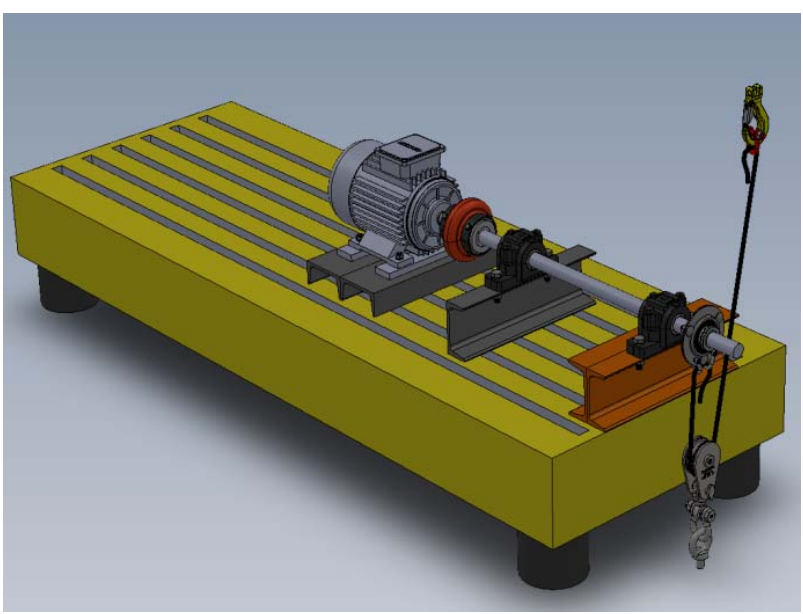

Figure 2. Test rig 3D model.

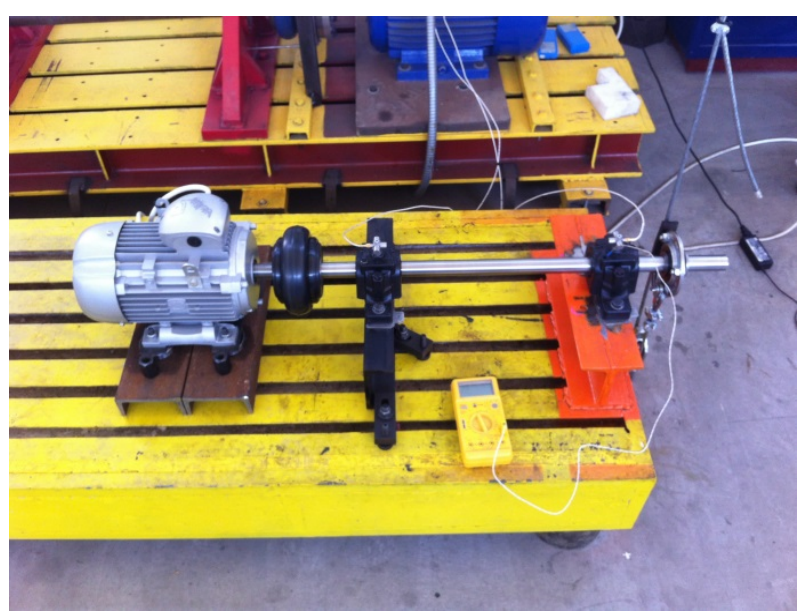

Figure 3. Photo of the test rig.

self-aligning double ball bearings in their housings. The shaft is coupled with a 3-phase AC motor using a donut type coupling arrangement, which can accommodate small axial and angular misalignments and ensures that the shaft is isolated and it is not affected by the motor's vibrations. The speed of the motor is controlled from a variable speed drive and it can be adjusted between 0 - 
$3000 \mathrm{rpm}$. The shaft is loaded using an arrangement consisted from an $8 \mathrm{~mm}$ wired rope, a pulley and a bearing with a flanged type of housing. An external load measured by a crane scale, forces the shaft radially downwards at its free end.

Three different types of bearings are used, having the same bore diameter. This selection has been made in order to use in each housing bearings with different characteristic frequencies and as a result to have a clearer indication about the source of the measured vibration signal. All bearings have tapered internal rings with a cylindrical bore diameter of $35 \mathrm{~mm}$ and they are mounted on the shaft with the use of proper conical adapter sleeves.

Two SKF type SNL 507 - 606 split type plummer housings have been selected. The test bearings are a SKF type 2207 EKTN9 double row self-aligning ball bearing in the rear housing (towards the motor side) and a SKF type 1207 EKTN9 double row self-aligning ball bearing in the front housing.

One SKF type PF73 flanged housing is used in the arrangement which is carrying the applied load in conjunction with an SKF type YSA 207-2FK single row deep groove ball Y-bearing which is sealed and greased for life.

Two Kistler type 8792A25T three-axial accelerometers are mounted with magnets on the top of the two plumper type housings. The accelerometers are capable of measuring acceleration amplitudes up to $25 \mathrm{~g}$. They are connected to Kistler type 5134/5134B amplifiers and their outputs are acquired by a HBM MGCplus data acquisition machine.

Visualization and processing of the signals is made through HBM CATMAN software installed on a Laptop PC. The communication between the data acquisition machine and the PC is made through a wired Ethernet connection. Also, a K-type thermometer is used in order to measure the shaft, bearings and housings temperatures and the ambient temperature.

\subsection{Measurements}

The load applied to the shaft through the first flanged housing bearing ranges from 0 to $2800 \mathrm{~N}$. This load results in loading the first housed bearing (front) with a range of $0-3500 \mathrm{~N}$ and the rear housed bearing with a range of $0-700 \mathrm{~N}$ respectively. The motor speed ranges from 0 to $3000 \mathrm{rpm}$.

Six channels are monitored and recorded, representing the three axes of each accelerometer. The naming of the axes is following the naming of the accelerometer's axes which is: $\mathbf{x}$ for the axis of the shaft, $\mathbf{z}$ for the axis of the load direction and $\mathbf{y}$ for the axis vertical to the plane $\mathbf{x z}$.

The sampling rate is set to 2400 samples per second (sampling frequency) for each channel. Measurements are conducted in different loading conditions and speeds and they are monitored in real time as raw signal representing the overall acceleration measurement. The signals are also recorded for further processing and the duration of each recorded measurement is set to 1 minute. These data are recorded and saved in. BIN type files which can be further processed with the aid of the appropriate software.

In one case, debris was added to the bearing lubricant in order to cause an artificial time-progressing bearing failure due to severe wear. This accelerated test aimed in demonstrating the effectiveness of the proposed condition monitoring method.

\section{Results and Discussion}

During the experiment various operating conditions were investigated regarding the rotational speed and the applied load. In these conditions it is obvious that the amplitude of the signal depends on the load. High loads and high speeds cause increased vibration amplitudes, which becomes even higher when a malfunction occurs and it also depends on the severity of the malfunction.

The measured signals are processed in time domain and in frequency domain. In time domain, changes in amplitude, peaks and rms values can be seen, but it is difficult to identify the root cause of these changes. Processing the values of the statistical variables (Equations (1)-(5)) does not give any useful results about the source of the vibrations and so the malfunctions of the system cannot be identified. The significance of the overall vibration amplitude is of great importance as the progress of the failure is visible and can trigger some alarms if appropriate levels are set. From the plotted data in Figure 4 it is shown that a failure in the rig can cause significant increase in the measured vibration signals.

Processing the acquired data in the frequency domain results in the identification of the true source of the vibrations and in the detection of possible faults. The characteristic frequencies of the bearing, as they are given by the manufacturer SKF, for a rotational speed of 2400 rpm are shown on Table 2. If a failure occurs in a

Table 2. Frequencies of potential damage in the tested ball bearings.

\begin{tabular}{cccc}
\hline \multirow{2}{*}{ Frequency } & \multicolumn{3}{c}{ Bearing } \\
\cline { 2 - 4 } & $\begin{array}{c}\text { SKF 1207 } \\
\text { EKTN9 'front' }\end{array}$ & $\begin{array}{c}\text { SKF 2207 } \\
\text { EKTN9 'rear' }\end{array}$ & $\begin{array}{c}\text { SKF YSA } \\
207-2 F K \text { 'load' }\end{array}$ \\
\hline$f$ & $40.0 \mathrm{~Hz}$ & $40.0 \mathrm{~Hz}$ & $40.0 \mathrm{~Hz}$ \\
$f_{c}$ & $16.8 \mathrm{~Hz}$ & $15.8 \mathrm{~Hz}$ & $15.8 \mathrm{~Hz}$ \\
$f_{b p f o}$ & $251.0 \mathrm{~Hz}$ & $190.0 \mathrm{~Hz}$ & $143.0 \mathrm{~Hz}$ \\
$f_{b p f i}$ & $349.0 \mathrm{~Hz}$ & $290.0 \mathrm{~Hz}$ & $217.0 \mathrm{~Hz}$ \\
$f_{r}$ & $119.0 \mathrm{~Hz}$ & $89.1 \mathrm{~Hz}$ & $92.1 \mathrm{~Hz}$ \\
$2 x f_{r}$ & $238.0 \mathrm{~Hz}$ & $178.0 \mathrm{~Hz}$ & $184.0 \mathrm{~Hz}$ \\
\hline
\end{tabular}


bearing, the amplitude of the relevant frequency is expected to increase. The frequencies for potential damages on the cage, the inner raceway, the outer raceway and on the balls respectively are $f_{c}, f_{\text {bpir }}, f_{\text {bpir }}, 2 x f_{r}$ respectively.

Spectral vibration analysis can show the cause of this increase amplitude by examining the behavior of the amplitude of each characteristic frequency band.

In order to reduce the spectral leakage and make the dominant frequencies easier to be identified, the power spectrum is used, where the outputs of the FFT are raised to the square.

In our case, a failure on the outer raceway can be identified as there is a peak on the vibration amplitude at the frequencies around $250 \mathrm{~Hz}$.

The failure is in its initial stage after 1 hour of opera- tion (Figure 5) but even then a peak on the characteristic frequency $f_{b p f o}$ is visible. After 12 hours of operation the characteristic frequency $f_{\text {bpfo }}$ is much more dominant and its amplitude has been increased dramatically. As it can be seen in Figure 6 the amplitudes of some frequencies have also been increased but they are relatively low compared to the amplitude of the frequency corresponding to a failure on the outer ring.

These snapshots of the frequency spectrum can be continuous with time intervals relevant to the PC's data processing capability. Series of such data can be plotted in a tridimensional plot style showing the progress of the amplitude in each characteristic frequency. A sample of such a plot is shown in Figure 7 where 5 samples are plotted.

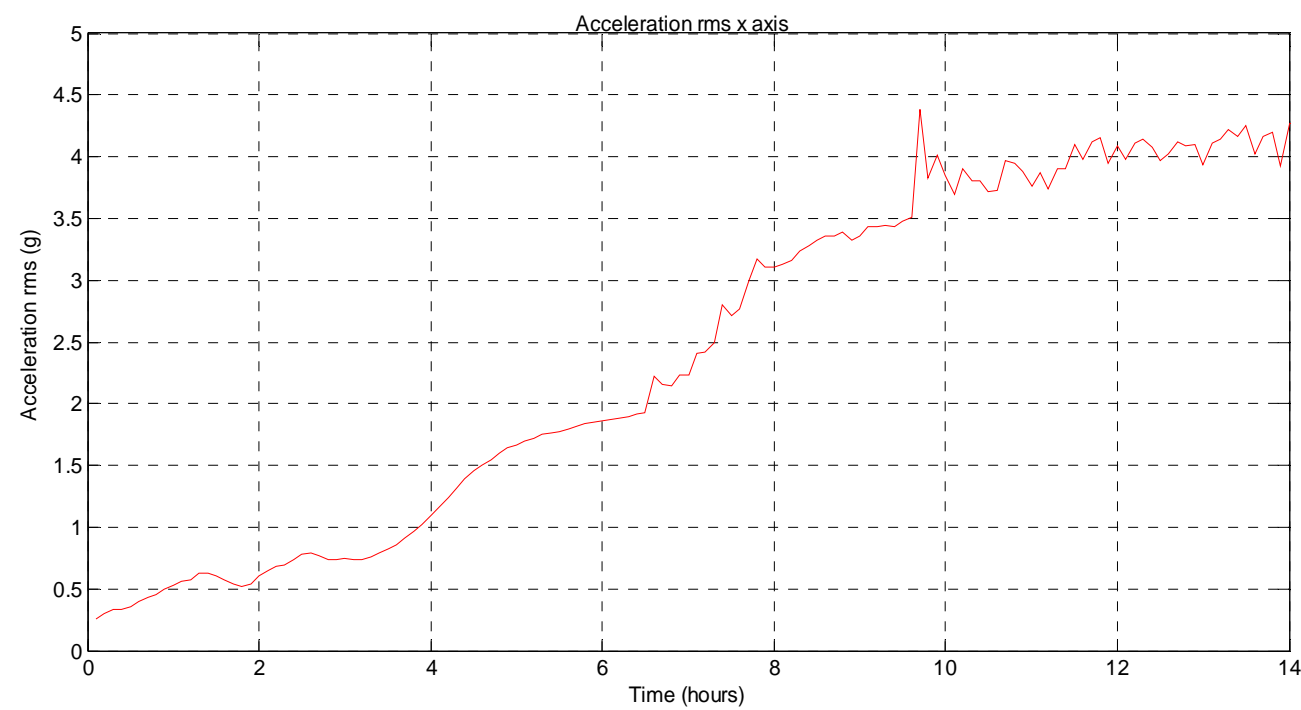

Figure 4. RMS value of acceleration on $\mathrm{x}$ axis of the "front" bearing during the experiment.

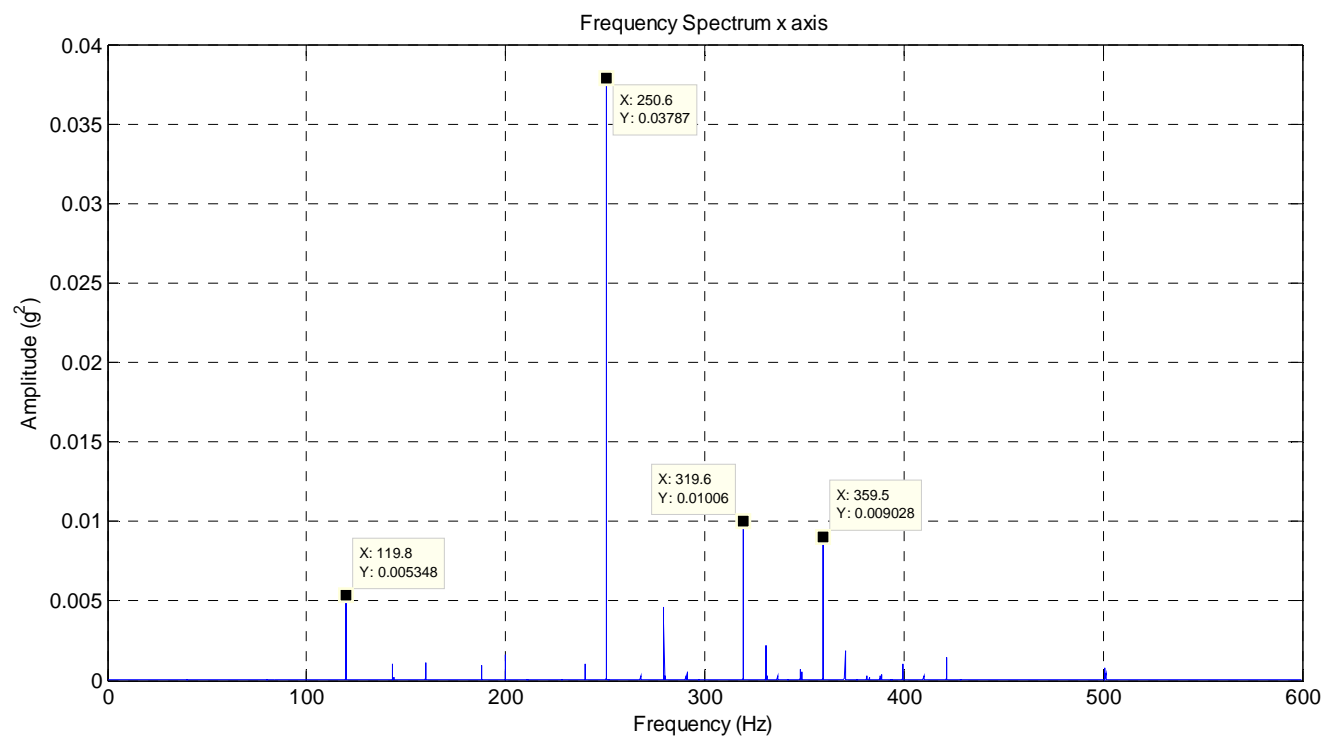

Figure 5. Frequency spectrum of the "front" bearing after 1 hour of operation. 


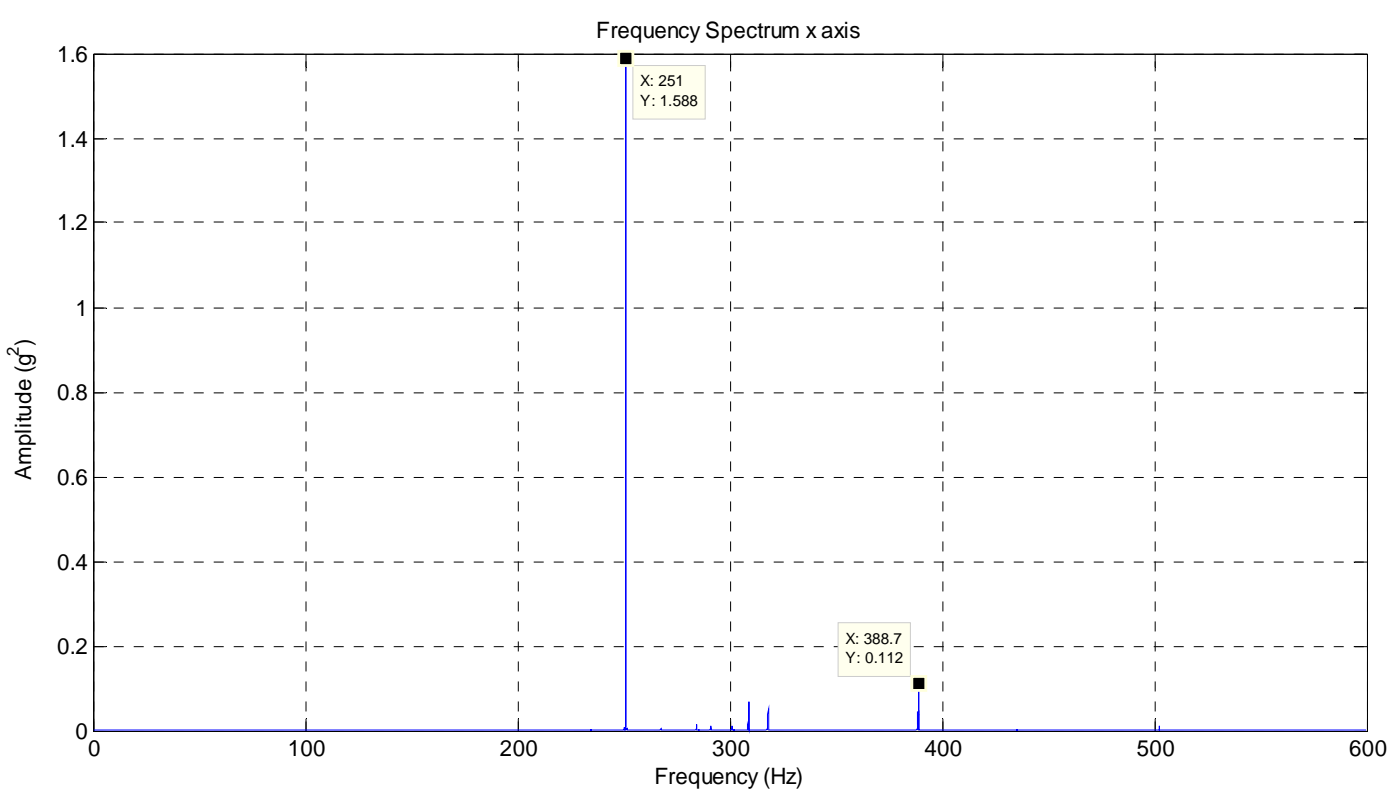

Figure 6. Frequency spectrum of the "front" bearing after 12 hours of operation.

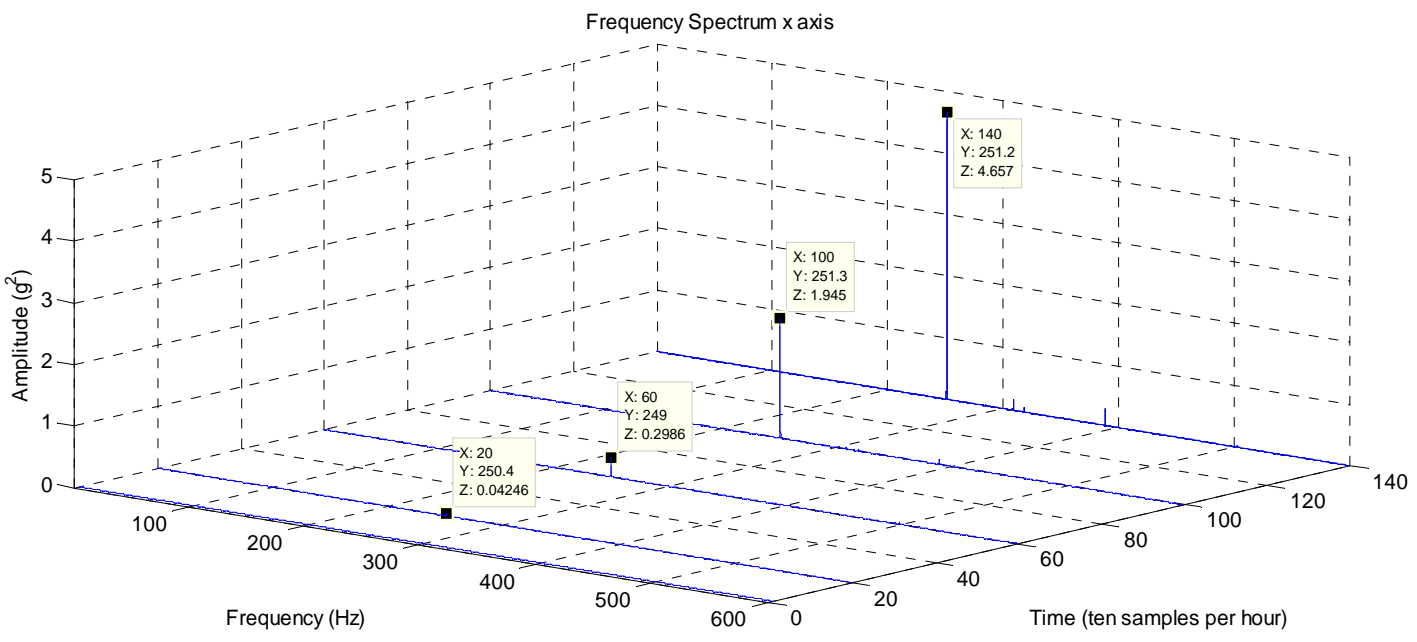

Figure 7. Evolution of the frequency spectra of the "front" bearing during the experiment.

The progress of the failure on the outer raceway is clearly seen. Starting from a rather low level until the $60^{\text {th }}$ sample (after 6 hours of operation), the vibrations at about $250 \mathrm{~Hz}$ are escalating reaching very high levels. These findings are in conformity with the rms value of acceleration in the time domain of the overall vibrations but in the frequency domain additional information can be extracted as the position of the fault on the bearing and on the test rig can be clearly identified.

The results of the experimental setup can be summarized in these points:

1) Vibration analysis in both time and frequency domains can give useful information about the operating conditions of wind turbines

2) Analysis in the frequency domain can be helpful in identifying the source of the increased vibrations

3) An almost real time monitoring in the frequency domain is possible when continuous FFT transforms of the measured signal are plotted

4) The amplitude of the signal of the potential damage frequencies increases as the failure progresses

\section{Conclusions}

Vibration monitoring is playing an increasingly important role as a tool for assisting predictive and preventive maintenance and for improving the operation efficiency and reliability of a plant through the design maintenance. When knowing the failure modes of a machine, it is possible to determine its condition and identify potential 
failures. This can be easily performed by analyzing the signal in the frequency domain and comparing it with the theoretical frequencies of potential failures.

In this experimental setup, vibration signals are monitored through a data collection machine with an Ethernet connection to a PC. Processing in the frequency domain is causing a time lag but this is not critical for identifying a potential progressing fault. The results of the tests show that the implementation of a vibration monitoring system on a wind turbine can be helpful in identifying and monitoring an occurring failure.

\section{REFERENCES}

[1] X. Chiementin, F. Bolaers, L. Rasolofondraibe and J.-P. Dron, "Localization and Quantification of Vibratory Sources: Application to the Predictive Maintenance of Rolling Bearings," Journal of Sound and Vibration, Vol. 316, No. 1-5, 2008, pp. 331-347.

http://dx.doi.org/10.1016/j.jsv.2008.02.029

[2] K. Debray, F. Bogard and Y. Q. Guo, "Numerical Vibration Analysis on Defect Detection in Revolving Machines Using Two Bearing Models," Archive of Applied Mechanics, Vol. 74, No. 1-2, 2004, pp. 45-58. http://dx.doi.org/10.1007/s00419-004-0327-8

[3] Z. Kıral and H. Karagulle, "Vibration Analysis of Rolling Element Bearings with Various Defects under the Action of an Unbalanced Force," Mechanical Systems and Signal Processing, Vol. 20, No. 8, 2006, pp. 1967-1991. http://dx.doi.org/10.1016/j.ymssp.2005.05.001

[4] H. Qiu, J. Lee, J. Lin and G. Yu, "Robust Performance Degradation Assessment Methods for Enhanced Rolling Element Bearings Prognostics,” Advanced Engineering Informatics, Vol. 40, No. 3-4, 2004, pp. 1-14. http://dx.doi.org/10.1016/j.aei.2004.08.001

[5] J.-P. Dron, L. Rasolofondraibe, X. Chiementin and F. Bolaers, "A Comparative Experimental Study on the Use of Three Denoising Methods for Bearing Defect Detection,” Meccanica, Vol. 45, No. 2, 2010, pp. 265-277. http://dx.doi.org/10.1007/s11012-009-9243-x

[6] A. Djebala, N. Ouelaa and N. Hamzaoui, "Detection of Rolling Bearing Defects Using Discrete Wavelet Analysis,” Meccanica, Vol. 43, No. 3, 2008, pp. 339-348. http://dx.doi.org/10.1007/s11012-007-9098-y

[7] Y. Ming, J. Chen and G. Dong, "Weak Fault Feature Extraction of Rolling Bearing Based on Cyclic Wiener Filter and Envelope Spectrum,” Mechanical Systems and Signal Processing, Vol. 25, No. 5, 2011, pp. 1773-1785. http://dx.doi.org/10.1016/j.ymssp.2010.12.002

[8] T. Karacay and N. Akturk, "Experimental Diagnostics of Ball Bearings Using Statistical and Spectral Methods," Tribology International, Vol. 42, No. 6, 2009, pp. 836843. http://dx.doi.org/10.1016/j.triboint.2008.11.003

[9] X. Niu, L. Zhu and H. Ding, "New Statistical Moments for the Detection of Defects in Rolling Element Bearings," International Journal of Manufacturing Technology, Vol. 26, No. 11-12, 2005, pp. 1268-1274.

\section{http://dx.doi.org/10.1007/s00170-004-2109-4}

[10] I. Zotos and Th. Costopoulos, "On the Use of Rolling Element Bearings Models in Precision Maintenance," American Journal of Engineering and Applied Science, Vol. 4, No. 2, 2009, pp. 344-352. http://dx.doi.org/10.3844/ajeassp.2009.344.352

[11] M. S. Patil, J. Mathew, P. K. Rajendrakumar and S. Desai, "A Theoretical Model to Predict the Effect of Localized Defect on Vibrations Associated with Ball Bearing," International Journal of Mechanical Sciences, Vol. 52, No. 9, 2010, pp. 1193-1201.

http://dx.doi.org/10.1016/j.ijmecsci.2010.05.005

[12] R. B. Randall and J. Antoni, "Rolling Element Bearing Diagnostics-A Tutorial," Mechanical Systems and Signal Processing, Vol. 25, No. 2, 2011, pp. 485-520. http://dx.doi.org/10.1016/j.ymssp.2010.07.017

[13] V. Sugumaran and K. I. Ramachandran, "Fault Diagnosis of Roller Bearing Using Fuzzy Classifier and Histogram Features with Focus on Automatic Rule Learning,” Expert Systems with Applications, Vol. 38, No. 5, 2011, pp. 4901-4907. http://dx.doi.org/10.1016/j.eswa.2010.09.089

[14] K. Raptis, G. Papadopoulos, Th. Costopoulos and A. Tsolakis, "Experimental Study of Load Sharing in RollerBearing Contact by Caustics and Photoelasticity," American Journal of Engineering and Applied Sciences, Vol. 4, No. 2, 2011, pp. 294-300. http://dx.doi.org/10.3844/ajeassp.2011.294.300

[15] I. Zotos nd Th. Costopoulos, “A Study on the Increase of Numerical Stability and Accuracy of the Transfer Matrix Method,” Journal of Mathematics and Statistics, Vol. 4, No. 4, 2008, pp. 208-212.

[16] Y. Lei, Z. He and Y. Zi, “A New Approach to Intelligent Fault Diagnosis of Rotating Machinery,” Expert Systems with Applications, Vol. 35, No. 4, 2008, pp. 1593-1600. http://dx.doi.org/10.1016/j.eswa.2007.08.072

[17] H. Wang and P. Chen, "Intelligent Diagnosis Method for Rolling Element Bearing Faults Using Possibility Theory and Neural Network," Computers \& Industrial Engineering, Vol. 60, No. 4, 2011, pp. 511-518. http://dx.doi.org/10.1016/j.cie.2010.12.004

[18] P. K. Kankar, S. C. Sharma and S. P. Harsha, "Fault Diagnosis of Ball Bearings Using Machine Learning Methods,” Expert Systems with Applications, Vol. 38, No. 3, 2011, pp. 1876-1886. http://dx.doi.org/10.1016/j.eswa.2010.07.119

[19] P. K. Kankar, S. C. Sharma and S. P. Harsha, "Fault Diagnosis of Ball Bearings Using Continuous Wavelet Transform,” Applied Soft Computing, Vol. 11, No. 2, 2011, pp. 2300-2312. http://dx.doi.org/10.1016/j.asoc.2010.08.011

[20] B. Kilundu, P. Dehombreux and C. Letot, "Early Detection of Bearing Damage by Means of Decision Trees," Journal of Automation, Mobile Robotics \& Intelligent Systems, Vol. 3, No. 3, 2009, pp. 70-74.

[21] P. Stepanic, I. V. Latinovic and Z. Djur, “A New Approach to Detection of Defects in Rolling Element Bearings Based on Statistical Pattern Recognition,” International Journal of Advanced Manufacturing Technology, 
Vol. 45, No. 1-2, 2009, pp. 91-100.

http://dx.doi.org/10.1007/s00170-009-1953-7

[22] T. I. Liu, J. H. Singonahalli and N. R. Iyer, "Detection of Roller Bearing Defects Using Expert System and Fuzzy
Logic,” Mechanical Systems and Signal Processing, Vol. 10, No. 5, 1996, pp. 595-614.

http://dx.doi.org/10.1006/mssp.1996.0041 